\title{
RISK MANAGEMENT AND BUILT HERITAGE: TOWARDS A SYSTEMATIC APPROACH
}

\author{
ANTHOULA KONSTA ${ }^{1 *}$ AND STEFANO DELLA TORRE ${ }^{1}$ \\ ${ }^{1}$ Department of Architecture, Building environment and Construction engineering (ABC) \\ Politecnico di Milano \\ 31 Ponzio St., 20133 Milan, Italy \\ e-mail: anthoula.konsta@polimi.it, stefano.dellatorre@polimi.it; www.abc.polimi.it \\ (*corresponding author)
}

Keywords: Risk Classification, Risk Assessment, Risk Management, Built Heritage Management

\begin{abstract}
This paper discusses the classification of risks as a tool for the identification, the assessment and the management of risks for the built heritage. Existing typologies of risk vary according to the selected criteria on which they are based and their utility within the risk management process. Indicative examples of risk classifications proposed and used in the field of cultural heritage management, as well as in other fields, are examined. The comparison of the selected criteria for analysing risks and the reflection upon their relevant aspects to the built heritage conservation provide a frame for a systematic approach to the built heritage management.
\end{abstract}

\section{INTRODUCTION}

During the last thirty years, the risk management methodology has been recognised as an effective approach to the conservation decision-making process. Among the various efforts that have been made to develop coherent and clear procedures for the risk management in the field of cultural heritage, the experience carried out in museums preventive conservation practices stands out.

With respect to the field of built heritage, we can notice the prevalence of a fragmentary vision of the problems and their solution. Indeed, many methods have been elaborated for the analysis of the different risks to which built heritage is exposed. From air pollution and acid rain to natural hazards, and from inappropriate intervention and use to mass tourism, we can find a relevant number of studies and practice involving respectively numerous specialists and skills from a variety of fields. Naturally, this kind of "separation" arises from the necessity to deepen the knowledge of the different problems and their solution and it cannot be undoubtedly considered as a stumbling block. The problem emerges from the difficulty to coordinate interdisciplinarity, to understand multifaceted problems, and to put together all the findings.

With the aim to frame a more methodical and holistic approach to the built heritage risk management, firstly, the different parts of a risk management process are examined, and their main characteristics, as well as their relationship are underlined. Secondly, different risk classification schemes are discussed with regard to their usefulness and practicality to respond to the diverse needs of the process. 


\section{RISK ASSESSMENT IN RELATION TO RISK MANAGEMENT}

\subsection{The importance of meaningful measurements for a successful risk management}

David J. Ball [1] in his article about the evolution of risk-based thinking describes the contribution of the studies of mathematicians and scientists during the 17th and 18th centuries to the development of risk based approaches to the first insurance companies. The mathematical calculation of the probability of future adverse events in a defined period and the wide range of its application has given rise, in the 20th century, to the extension of risk management approaches from the financial and insurance sectors to the industrial and public health sectors

Similarly, Douglas W. Hubbard in his brief history of risk management highlights the determinant role of probability theory and statistics in assessing risks: "[...] throughout most of human history, we were dealing with only half of the risk management problem, at most. From Babylon through the Middle Ages, risk management was an unguided mitigation of risks. Choosing what risks to prepare for was always a matter of gut feel. What differentiates risk management since the start of the Age of Enlightenment is in part a more systematic approach to assessing the risk. The development of probability theory and statistics in the 17 th century allowed for risk to be quantified in a meaningful way" [2, p. 22].

However, Hubbard warns that the predominant approach to risk management is not based on actual measurements of risks. Indeed, the probabilistic models will be adopted only in select industries for select applications, such as the quantitative methods used in insurance and many of the risk analysis techniques adopted and widely used by based on arbitrary and or empirical analysis. In addition, he concludes, on meaningful measures, the risk mitigation bound to address the wrong problems. If risk
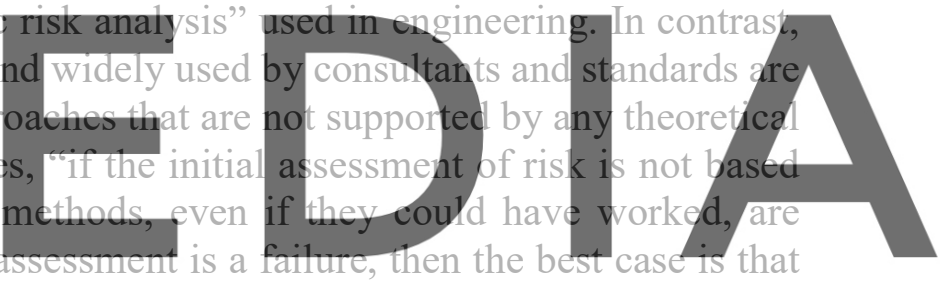
risk management effort is simply a waste of time and money because decisions are ultimately

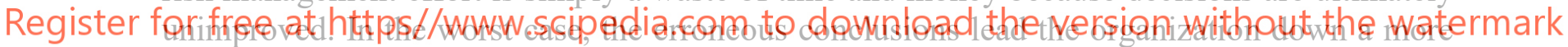
dangerous path that it would be probably not have otherwise taken" [2, p. 6].

\subsection{Risk analysis for better decisions}

The big influence of risk-based approaches over all the agencies has been determined not because of the willingness to reduce all risks (Ball considers three factors, firstly the lack of resources, secondly the non-exclusive interest for risks, and thirdly the positive aspects of risky activities), but as a consequence of the capacity to prioritise the activities when managing a great number of risks, and above all to reach efficient decisions [1].

In this perspective, the definition of acceptable-risk problems and the critical analysis of the viability of various approaches to decision making offered by Fischhoff et al [3] is very relevant. As stated in their report, "risk acceptable problems are decision problems, i.e. they require a choice between alternatives. That choice depends upon the alternatives, values, and beliefs that are considered" [3, pp. ii, 4-6]. As for the decision making methods, three categories have been identified and analysed: professional judgment, bootstrapping techniques and formal analysis, such as the cost/benefit analysis or the multi-criteria analysis.

Similarly, Kaplan and Garrick [4] in the light of two quantitative definitions of risk they 
discussed the notion of risk acceptability and argued that "[...] the purpose of risk analysis and risk quantification is always to provide input to an underlying decision problem which involves not just risks but also other forms of costs and benefits. Risk must thus be considered always within a decision theory context. Within this context, that risk is acceptable, which comes along with the optimum decision option, all other risks are unacceptable, even if smaller".

Thus, risk assessment is only one phase in the process of risk management. It is the technical estimation of risks or else the "tool of gaining knowledge about the risks" and consists in identifying hazards, assessing their probabilities and measuring their consequences [5]. The other phase regards the decision process and includes further considerations, incorporating social and economic concerns as well as legal requirements and policy issues $[1,6]$. In other words, "risk analysis is only part of decision analysis and analysis is only part of any kind of management - risk management or otherwise" [2, p. 242].

\subsection{Parts and content of the risk management process}

The review of the main current approaches to risk in a wide set of environments, provided by the International Risk Governance Council IRGC [5, pp. 86-156], comes to the conclusion that although there is a lack of consistency in the use of terms, as well as different emphases placed on the parts of the risk management process, the basic processes involved in assessing and managing risks are to a great extent the same.

Thus, without dwelling on the terminology differences between the wide range of organisations and pubtications concerning risk management, the intention is to understand the
logic and the function of the common process phases or else, as Hubbard proposed, a simplified
risk management cycle. Necessary conditions of an informed risk mitigation is first to identify
and then to assess risks. Although there are cases of easily understood risks that can be
addressed apparently without great assessment efforts, in most situations there is a large namber
of risks, with different potentiat risk mitigation strategies but only a restricted availabulity of resources. For this reason, it is necessary to assess not only the initial risks but also the expected

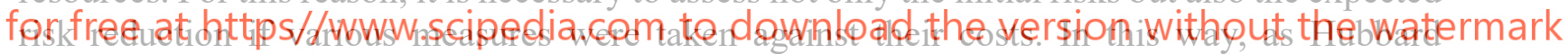

underlines, "risk assessment appears prior to and as part of the selection of risk mitigation methods". Once the mitigation options have been selected and implemented, they have to be monitored with the same manner and the risk management cycle is about to begin again [2, pp. 30-31].

\section{RISK CLASSIFICATION SYSTEMS IN THE FIELD OF MUSEUMS}

The publication of The ABC Method: a risk management approach to the preservation of cultural heritage in 2016 represents the updated version of the risk management practices developed by the Canadian Conservation Institute, the ICCROM, and the Netherlands Cultural Heritage Agency [7]. The manual, based on the experiences carried out in the field of museums since $1980[8,9,10]$, is built around the five principal steps of a risk management process $[11,12]$, and provides detailed explanations about tasks and activities for the implementation of each step.

Two aspects are of particular interest for the purpose of this study. The first one regards the use of frameworks "for thinking about risks in the identify, analyse and treat steps" [7, p. 69]. Five classification schemes are proposed based on "agents", "types", "stages", "layers", and 
"sources of knowledge".

The ten agents of deterioration are used to identify risks and serve as channels to organise all the scenario paths from hazards to adverse effects [7, pp. 70-72].

In terms of occurrence, risks can be classified in three practical types, i.e. rare events, common events, and cumulative processes, with the aim to "guide the risk discovery process, to guide the location of information during the analyse step, and to guide thinking during the treat step" [7, p. 73].

The analysis of risks according to the five stages of control - corresponding to preventive conservation (1. avoid sources of the agent, 2. detect the agent, 3. block the agent, 4. respond to the agent), disaster planning (5a. recover from the fast agent), and remedial conservation/restoration (5b. recover from the slow agent) [8] - ascertains the feasibility and the effectiveness of the risk treat options [7, pp. 75-76].

As for the six layers - region, site, building, room, fittings, packaging/support, and items besides being useful for the analysis of the block stage of control, they organize possible sources of hazards and agents of deterioration, as well as they structure the knowledge and expertise needed for the analysis [7, pp. 77-78].

The last framework of the three sources of knowledge is closely related to the three types of occurrence. Regional statistics is the source of knowledge about the frequency/intensity of rare events; local knowledge (surveys) is the source for common events, the intensity of cumulative hazards, the five stages of control and the local layers; scientific and technical knowledge is the source for the sensitivity to cumulative processes and for most theories that can analyse risks [7, p. 79].
The second aspect concerns the quantification of risks. The two basic criteria, probabifity
and consequences, have been formulated in order to place events and cumulative processes/side
by side and to include the relative importance/significance of the various items of the collection
[7, p. 17]. The formen becomes Frequency (for events) or Rate (for cumulative processes) and the latter is called Loss of value and is divided into two parts, the fractional loss of value to

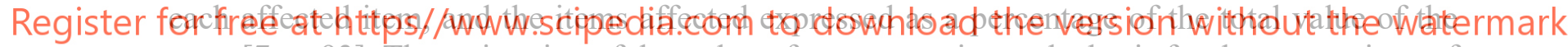
asset $[7$, p. 93]. The estimation of these three factors constitutes the basis for the comparison of risks.

Following the common practice in risk assessment of distinguishing between the technical components of risk analysis and the subjective components, i.e. the value judgements, the manual affirms the necessity to provide a clear description of the two stages in derivation of the loss of value to each affected item: the expected damage in technical terms and the impacts on value [7, p. 129]. As stated in the manual "comparing risks with different kinds of deterioration requires the adoption of a common scale to convert the predicted deterioration into predicted loss of value. This is the hard part of comparative risk assessment and the essential part. It links material science to cultural values" [7, p. 23]. In addition to the loss of value, criteria such as uncertainty, constraints, opportunities, or the cost-effectiveness of options and the cost of options can be assessed and used during the risk evaluation phase [7, pp. 134-138, 142].

\section{RISK CLASSIFICATIONS SYSTEMS IN THE FIELD OF BUILT HERITAGE}

\subsection{Classifications based on "hazard" and "vulnerability" categories and levels}

The first example taken into consideration is the Risk Map of Cultural Heritage developed 
by the Italian Central Restoration Institute (ICR) [13]. The division in three groups made by Risk Map attempts to the characterisation of the risks according to three hazard categories and the corresponding vulnerability aspects of the building elements that have to be considered. In detail, the three clusters defined, the environmental-air domain, the static-structural domain, and the anthropic domain, connect the three diverse nature of risk factors - i.e. the climatic/microclimatic and air pollutants risk factors, the geomorphological characteristics of the ground and of the subsurface, and the demographic/socio-economic dynamics - to the three different aspects of vulnerability defined by the material surface characteristics, the structural characteristics and the use/safety aspects of the building.

Even if the taxonomy is referred to the nature (climatological, geophysical, and anthropic) of risk factors and the building vulnerability aspects, we can notice that the two of the three types defined are equal to the types defined by Waller. Indeed, in the first category of rare/catastrophic risks we can link the static-structural domain, where the hazards considered are: seismic, landslides, floods, coastal dynamics, avalanches and volcanic, i.e. with low probability but severe effects, involving the structure of the building. In the third category of constant/mild-gradual risks we can associate the environmental-air domain characterised by threats, such as temperature, precipitation, wind, air humidity, pollution etc., that have cumulative effects on the surfaces of the building materials.

Another project that follows the same groups of risks with Risk Map is the European CHIC protocol [14]. In this case, the distinction between certain/long term and uncertain/rapid onset effects for the natural risks is clarified

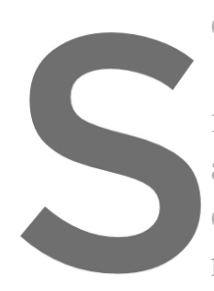
Similarly to the thre identification of risks, t and finally guide thinki explains, is significant in may not justify preventiv they organ
ing in the
in the risk
ive action of risks defined
anise the knowl
he treat step. M
k management
ns, whereas a s. led in musetim co and the ex
loreover, this so
process. A rapid
slow acting agen collections, they contr
expertise necessary for
sort of classification, a
id onset event with low tribute to the
r the analysis
as Baer [15]
to affect with certainty the elements exposed may is a reason to take immediate action. On the other hand, the

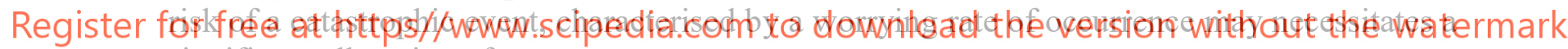
significant allocation of resources.

As for the measurement of risks, Risk Map considers three different detail levels according to the scale considered: territorial, individual, and local risk. The territorial risk is based on the hazard and exposure indicators related to the municipal area; the individual risk concerns the hazard indicator of the municipal area combined with the vulnerability of a single building; and lastly the local risk that relates the indicator of local hazard with the building vulnerability.

Recent developments of Risk Map tool concern the elaboration of a new evaluation model of seismic risk by updating the indicators of seismic hazard and vulnerability according to the new recommendations for the assessment and mitigation of seismic risk to cultural heritage approved in 2011 [16], as well as a proposal to adapt the tool to the characteristics of the buildings in historical centres [17].

\subsection{Classification schemes based on "nature", "temporality", "scale" and "probability" of risk factors.}

Another example of risk classification schemes for the built heritage is Dario Camuffo's work "Perspectives on risk to architectural heritage" [18], in which the author compiles a list 
of the major risk factors. He focuses on the problems related to the physicochemical decay of the buildings and discusses the gaps in our scientific and technological knowledge, the controversies over the interpretation of results, and the latest trends. At the end of the chapter proposes a classification of selected risk factors to cultural heritage. The risk factors are divided in two large groups, natural and anthropogenic and qualitative indications of "nature", "temporality", "scale", and "probability" are given.

With regard to the nature, risk factors are characterised mainly by a physical, chemical, or biological action. Concerning the temporality, they are separated in long term, medium term and rapid onset, while in respect of the scale, they can be local, regional, and global. As for the probability, risk factors vary from rare, infrequent and frequent events, to continuous cycles and continuous. Although the criteria and the various categories proposed in this table by Camuffo are not new, on the contrary they are commonly used in the conservation field, this work gains importance because of its holistic and systematic approach. Indeed, the organisation of the major threats to which is exposed built heritage and their qualitative characteristics contributes to their understanding and their management.

\subsection{Classification schemes based on "cause-effect" relationships, "building materials",} "building elements", and "building typologies"

Another common risk classification scheme in the field of build heritage is the consequencebased approach. In fact, thanks to several efforts matured in architectural preservation field, guided procedures for the analysis of the decay/damage have been intreduced in national and international recommen situ investigations, and Indicative examples development of a Structirc
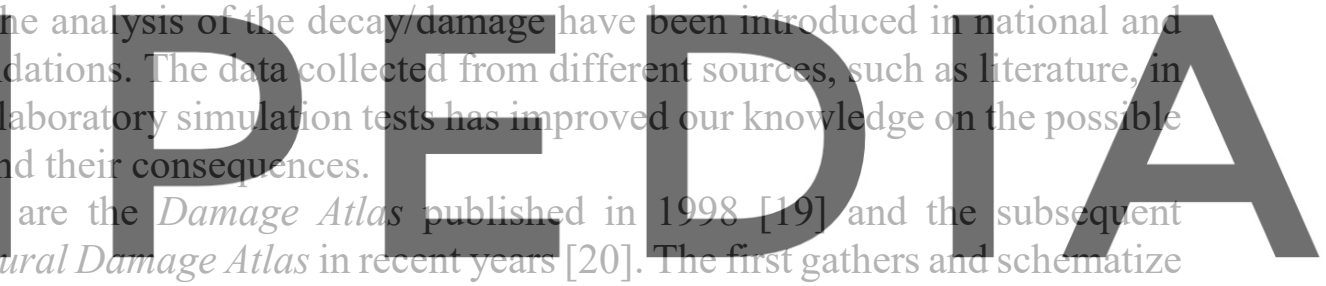
into relations between damage types, causes and deterioration processes the current knowledge

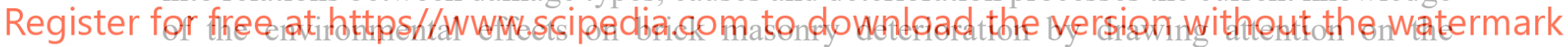

complex interaction of different materials and different boundary conditions [21]. The second focuses on the mechanical behaviour of brick- and stonework masonry under different actions, caused by sudden events such as earthquakes, floods etc. or by long term phenomena such as soil settlement, heavy loads and lack of maintenance, and forms a basis for the definition of typical structural damage patterns.

Without going into details, the damage classification concerning the structural behaviour and the failure mechanisms of the building elements takes into account not only the construction materials, but also the different building typologies and the role of the various structural elements and their connections.

\subsection{Classification schemes based on the "combination of risk factors" and the "risk level change" in the course of time}

During the last years, the studies on the effects of the environmental factors on the cultural heritage have drawn attention to the issues related to climate change and the new pressures that will be caused by variations in temperature and precipitation, changes in soil conditions, groundwater and sea level, and extreme climatic events. 
The Noah's Ark project has developed quantitative models for the global climate change impacts on the deterioration of different heritage materials on European geographical scale [22]. The results of the research project, gathered in different types of maps, correspond to the methodological approach adopted. Firstly, "climate maps" were elaborated by selecting the traditional climate parameters, both meteorological and pollution, relevant to cultural heritage. Estimations were carried out by taking into account different future scenarios and three periods, recent past, near future and far future. In order to obtain the most critical synergetic effects for the historic building materials, the previous climate maps were combined and specific "heritage climate maps" were produced, representing the advancement of the conservation science to adapt the classic meteorology to the needs of conservation [18]. The next step regarded the quantitative expression of damages or else the development of damage functions for the different building materials, based on different information sources, such as field data, literature survey, and laboratory investigations. The results were translated into "damage maps" which in their turn were summarized in "risk maps", showing the type of risks that are likely to increase or decrease in the different regions of Europe.

Among the various classification schemes used in this example, two of them stand out. On the one hand, the examination of synergetic effects based on the combination of different risk factors is necessary for the identification and the assessment of risks for different materials.On the other, the reflection on the risk level change in the course of time becomes useful for the understanding of the priorities and the need of measures.
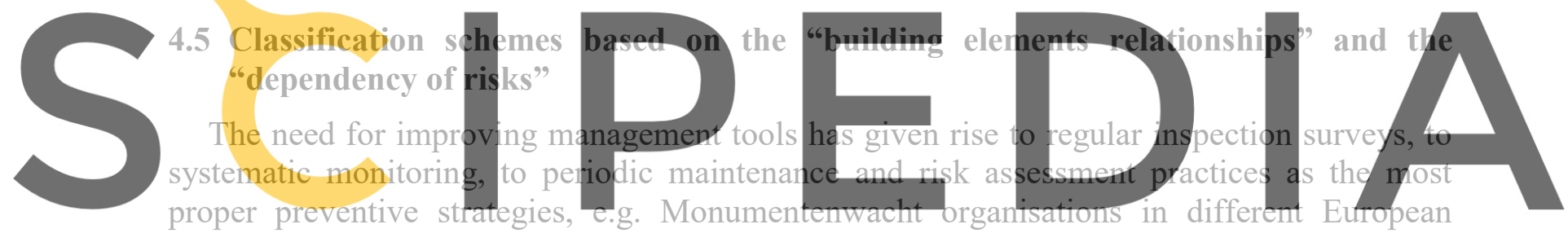

countries, Maintain our Heritage in UK, Preventive and Planned Conservation in Italy, the



standard Conservation of cultural property - Condition survey of immovable heritage [28] integrates the risk assessment with the condition assessment and represents an attempt to implement preventive strategies.

In the first draft of the standard, despite the consideration of relevant aspects related to the analysis of risks during the phase of assessment, the identification of the related measures was not based on the previous analysis or rather it was not based in an explicit way. Indeed, the activities of condition and risk assessment were not separated and the classification of measures was linked directly to the condition classes. The final version of the standard, approved in 2012, has resolved the previous ambiguities firstly by pointing out the difference between condition and risk assessment, and secondly by setting up a classification of urgency categories, i.e. urgent and immediate, short term, intermediate term, and finally long term, connected to the risk analysis. This sort of classification, based not only on the level of risk but also on the risk level change in the course of time (or the velocity of damage progression), as it has already been mentioned in the previous paragraph, is essential for the planning of the necessary measures.

Another important aspect of the risk analysis that the document proposes is the relationships between the building components. In fact, the description of the elements interactions is 
fundamental for the understanding of the unity and the complexity of the building system. For instance, the four basic interaction modalities between the various building technological elements suggested by the Italian guidelines for the conservation plan contribute to the better understanding of the effects that could be caused by the changes of the conditions of the elements in the course of time and in relation with the use of the building [26, pp.41-42]. Another example is the classification of typical seismic damage of the immovable artistic assets according to their connection with the structural elements proposed by the PERPETUATE project [29].

\subsection{Classification based on "risk reduction measures", their "control level" and the "time of action"}

The most important international organizations, such as UNESCO, ICOMOS, ICCROM, Council of Europe, etc., have strengthened their activities to develop operative methods for an overall prevention and mitigation strategy for the protection of cultural heritage against disasters. For example, the Risk-Preparedness Manual for World Cultural Heritage in 1998 [30] and Between Two Earthquakes in 1987 [31] are two of the first publications in a series of handbooks that is still being added to and updated in view of current concerns related mainly to the risks of climate change faced by cultural heritage.

The planning framework proposed in these manuals usually takes into account three elements: the action time, i.e. the preparedness (before), the response (during), and the recovery role of public institution

Apart from a guide against disasters, this sc exposed according to th measures $[32,33]$. What is more, this classifict
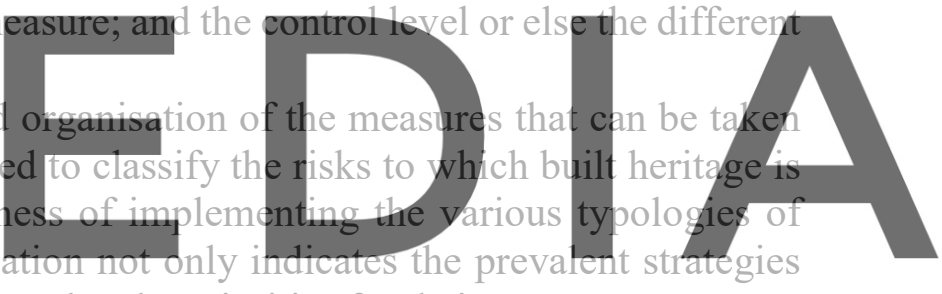
for the prevention/mitigation of risks but defines also the priorities for their assessment.

Register for free at https//www.scipedia.com to download the version without the watermark 5 RISK CLASSIFICATION SCHEMES PROPOSED IN OTHER FIELIDS

The most common approaches to the classification of risks employed in other fields, e.g. in insurance and financial industry, in the safety engineering field, or in health and environmental sector, are based on causal agents, risk events, and their potential consequences.

A different approach was developed by WBGU [34], and reviewed later by IRGC [5]. It is based on the concept of systemic risk, i.e. draws attention to the interdependencies and interactions between environmental, social, financial, and economic risks and opportunities. As Klinke and Renn [35] argue there are two key elements that characterise this approach, firstly the extension of factors that should be taken into consideration when managing systemic risks and secondly, the inclusion of analytic-deliberative processes in the regulatory framework.

In detail, the analysis increases the number of criteria, from two- the two classic components of risk, probability and magnitude of damage- to eight, by adding other physical and social impact categories, i.e. the incertitude, the ubiquity, the persistency, the reversibility, the delay effects, and the potential of mobilization.

Considering these criteria, four risk clusters have been identified, according to the different states of knowledge for each risk, distinguishing between 'simple', 'complex', 'uncertain' and 
'ambiguous' risk problems. "The characterisation of a particular risk depends on the degree of difficulty of establishing the cause-effect relationship between a risk agent and its potential consequences, the reliability of this relationship and the degree of controversy with regard to both what a risk actually means for those affected and the values to be applied when judging whether or not something needs to be done about it" [5, p. 12]. Based on these risk categories different strategies have been defined for both risk assessment and risk management, as well as about the level and the form of stakeholder participation, supported by suitable methods and tools.

The importance of this classification lies, on the one hand, in the acknowledgement of social, political and cultural contexts, as well as of individual and cultural value judgments, beyond the level of risk, that influence the acceptability/tolerability evaluation of risks (34, p. 29; 5, p. 37]. On the other hand, it allows flexibility in regard to the appropriate position of decisionmaking concerning the acceptability/tolerability of a risk by assisting assessors and managers in assigning, or dividing this judgement task through the consideration of its two distinct components, the evidence-based and the value-based component [5, pp. 37, 40].

These two factors become relevant to the management of built heritage. The concern about the broader context of the built heritage and their coevolutive relationship, as well as the maturing of sustainable principles, and the necessity of a long term perspective [36] can be reflected by the above systemic approach.

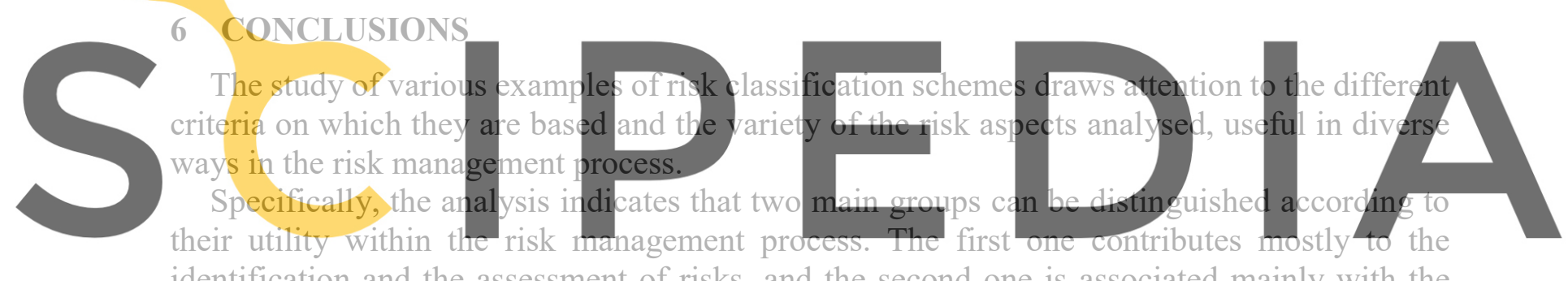
identification and the assessment of risks, and the second one is associated mainly with the

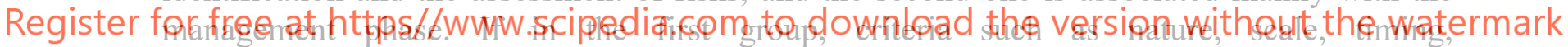
probability/frequency, severity, relations and consequences of risk factors play a part in establishing and/or estimating cause-effect relationships, in the second group, the criteria suggest priorities, strategies, and their efficiency.

In fact, these sorts of classifications have been already applied in an organised manner to the risk management methodology elaborated by the museum sector as it is shown in the example taken into consideration here. Concerning the built heritage conservation, it can be noticed that the various classification schemes proposed and analysed have not been incorporated into a systematic risk management methodology.

In this perspective, the overview provided in this paper represents an attempt to frame a more methodical and holistic approach to the built heritage risk management. In other words, the combination of different classification schemes could be integrated with the various phases of risk management in order to respond adequately to the diverse needs of the process.

However, the different classification schemes analysed in this study cannot be considered exhaustive. The examples that are presented here cover basic and generic classes of risk and they are indicative. According to the particularities of each case, the classifying criteria can be adapted to the specific needs and more precise categories can be formed. Thus, the 
methodological approach suggested depends not only on the different needs of the process but also on the needs of the specific built heritage case.

Table 1: Different risk classification schemes according to the selected criteria on which they are based and their utility/scope within the risk management process



\section{REFERENCES}

[1] Ball, D.J. The evolution of risk assessment and risk management: a background to the development of risk philosophy, Arboricultural Journal (2007) 30(2): 105-112.

[2] Hubbard, D.W. The failure of risk management: why it's broken and how to fix it. New Jersey: John Wiley \& Sons (2009).

[3] Fischhoff, B., Lichtenstein, S., Slovic, P., Derby, S.L. and Keeney, R.L. Approaches to Acceptable Risk: A Critical Guide. Work Performed for U.S. Nuclear Regulatory Commission under NRC Interagency Agreement 40-550-75. Oak Ridge National Laboratory, operated by Union Carbide Corporation for the Department of Energy (1980). 
[4] Kaplan, S. and Garrick, B.J. On the quantitative definition of risk. Risk Analysis (1981) 1(1).

[5] Renn, O. (ed.), White Paper on Risk Governance: Towards an Integrative Approach. Geneva: International Risk Governance Council (2005).

[6] Watt, J.M. The management of risk with respect to cultural heritage - a case study, Arboricultural Journal (2007) 30(2): 175-185.

[7] Michalski, S. and Pedersoli J.L. (eds), The ABC Method: a risk management approach to the preservation of cultural heritage. Ottawa: CCI, ICCROM (2016).

[8] Michalski, S. An overall framework for preventive conservation and remedial conservation. In: ICOM Committee for Conservation, 9th triennial meeting, Dresden, German Democratic Republic, 26-31 August 1990, preprints, ICOM Committee for Conservation (1990), pp. 589-591.

[9] Waller, R. Conservation risk assessment: a strategy for managing resources for preventive conservation. Studies in Conservation (1994) 39(sup2): 12-16.

[10] Waller, R. Risk management applied to preventive conservation. In: C.L. Rose, C.A. Hawks, H.H. Genoways (eds), Storage of natural history collections: A preventive conservation approach, New York: Society for the preservation (1995), pp. 21-27.

[11] Joint Standards Australia / Standards New Zealand Committee OB-007, Risk Management, AS/NZS 4360 (2004).

[12] ISO International Organization for Standardization, Risk Management, ISO 31000 (2018).

[13] Accardo, G., Giani, E. and Giovagnoli ,A. The Risk Map of Italian Cultural Heritage, Journal of Architectural Conservation (2003) 9(2): 41-57.

[14] eu-chic.eu. Eu-CHIC project official website. [online] Available at: http://www.eu-chic.eu/ [Accessed Oct. 2019].

[15] Baer, N.S. Assessment and management of risks to cultural property. In N.S. Baer, C. Sabbioni, A.I. Sors (eds), Science, Technology and European cultural heritage, proceedings of the European Symposium, Bologna, Italy 13-16 June 1989, Luxembourg: ECSC-EEC-EAEC (1991), pp.27-36.

[16] Cacace, C. and Donatelli, A. Carta del Rischio del patrimonio culturale: studio sulla vulnerablità e pericolosità sismica del patrimonio culturale in Sicilia e Calabria. In S. Della Torre and M.P. Borgarino (eds), Proceedings of the International Conference Preventive and Planned Conservation, Monza, Mantova - 5-9 May 2014, Protezione dal rischio sismico, Milano: Nardini editore (2014), pp.107-118.

[17] Cacace, C. and Fiorani, D. Centri storici, vulnerabilità, rischio e gestione della conservazione. Una proposta d'implementazione dello strumento Carta del Rischio. In S. Della Torre and M.P. Borgarino (eds), Proceedings of the International Conference Preventive and Planned Conservation Monza, Mantova - 5-9 May 2014, Protezione dal rischio sismico, Milano: Nardini editore (2014), pp. 119-128.

[18] Camuffo, D. Perspectives on risks to architectural heritage. In: N. S. Baer and R. Snethlage (eds), Saving our architectural heritage: the conservation of historic stone structures, New York: John Willey \&Sons Ltd. (1997), pp. 63-92.

[19] Franke, L., Schumann, I., van Hees, R., van der Klugt L, Naldini. S., Binda, L., Baronio, G., Van Balen, K. and Mateus, J. Damage Atlas - Classification and Analyses of Damage Patterns found in Brick Masonry. Project EV5V-CT92-0108, Research report No 8, Volume 2, Stuttgart: Fraunhofer IRB Verlag (1998). 
[20] Binda L., Saisi A., de Vent, I.A.E., Van Hees, R.P.J. and Naldini, S. Structural Damage in Masonry: Description and interpretation of crack patterns as basis for finding the damage causes. Restoration of buildings and monuments, Bauinstandsetzen und Bauenkmalpflege (2010) 16(2), pp. 1-22.

[21] Van Hees, R., Binda, L., Van Balen, K. and Naldini, S. Expert system for evaluation of deterioration of ancient brick masonry structures. The science of the Total Environment (1996) 189/190, pp. 247-254.

[22] Sabbioni, C., Brimblecombe, P. \& Cassar, M. (eds), The atlas of climate change impact on European cultural heritage: scientific analysis and management strategies. London, New York: Anthem Press (2012).

[23] Van Balen, K. and Vandesande, A. (eds), Innovative built heritage models. London: Taylor and Francis Group (2018).

[24] Journal of Cultural Heritage Management and Sustainable Development (2018) 8(2), Special Issue: Preventive and planned conservation approaches for built heritage management.

[25] Dann, N. Planned and preventative conservation and England: experiences, opportunities and requirements. In: Preventive and planned conservation: proceedings of the international conference. Vol 4: Metodi e strumenti per la prevenzione e la manutenzione, Monza - Mantova, 5-9 May 2014, Firenze: Nardini (2014), pp. 1-10.

[26] Della Torre, S. (ed.), La conservazione programmata del patrimonio storico architettonico. Linee guida per il piano di manutenzione e consuntivo scientifico. Milano: Guerini \& associati (2003).

[27] Moioli, R. and Baldioli, A. Conoscere per conservare. Dieci anni per la conservazione programmata. Quaderni dell'Osservatorio, 29. Milano: Fondazione Cariplo (2018).

[28] CEN/TC 346 - Conservation of Cultural Heritage. Conservation of cultural property Condition survey of immovable heritage, EN 16096 (2012).

[29] Abbas, N., Calderini, C., Cattari, S., Ginanni Corradini, R., Lagomarsino, S., Marghella, G., Piovanello, V., and Rossi, M. PERPETUATE FP7 - Theme ENV.2009.3.2.1.1 ENVIRONMENT Grant agreement $n^{\circ}$ : 244229, Deliverable D4 (2010), pp. 78-94.

[30] Stovel, H. Risk preparedness: a management manual for world cultural heritage. Rome: ICCROM (1998).

[31] Feilden, B. Between two earthquakes: Cultural property in seismic zones. Rome, California: ICCROM, Getty Conservation Institute (1987)

[32] Della Torre, S. The management process for built cultural heritage: preventive systems and decision making. In: K. Van Balen, A Vandesande,. (eds), Innovative Built Heritage Models. London: Taylor and Francis Group (2018), pp. 13-20.

[33] Presidenza del Consiglio dei Ministri (PCM), Struttura di Missione Casa Italia. Rapporto sulla Promozione della sicurezza dai Rischi naturali del Patrimonio abitativo (2017).

[34] WBGU, German Advisory Council on Global Change, World in transition. Strategies for managing Global Envirinmental Risks. Annual Report 1998. Berlin: Springer (2000).

[35] Renn, O., and Klinke, A. Systemic risks: a new challenge for risk management, EMPO reports (2004).

[36] Della Torre, S. A coevolutionary approach to the reuse of built cultural heritage. In: G. Biscontin, G. Driussi, (eds), Il patrimonio culturale in mutamento. Le sfide dell'uso. Venezia: Arcadia Ricerche (2019), pp. 25-34. 